AKSIOMA: Jurnal Program Studi Pendidikan Matematika

DOI: https://doi.org/10.24127/ajpm.v9i1.2657

\title{
OPTIMALISASI MOTIVASI DAN PRESTASI BELAJAR MENGGUNAKAN MOODLE BERBANTUAN COMPUTER ALGEBRA SYSTEM (CAS)
}

\author{
Kamhar Ngado ${ }^{1}$, Rosnawati ${ }^{2}$, Heri Retnawati ${ }^{3}$, Sri Andayani ${ }^{4}$ \\ ${ }^{1,2,3,4}$ Pendidikan Matematika, Universitas Negeri Yogyakarta \\ E-mail: $\quad$ kamhar.ngado.id@gmail.com ${ }^{1)}$ \\ rosnawati_uny@yahoo.com ${ }^{2)}$ \\ retnawati_heriuny@yahoo.com ${ }^{3}$ \\ andayani@uny.ac.id $^{4)}$
}

Received 23 January 2020; Received in revised form 19 February 2020; Accepted 28 March 2020

\begin{abstract}
Abstrak
Tujuan dari penelitian ini adalah untuk mengetahui adakah pengaruh website eLearning Moodle berbantuan Computer Algebra System (CAS) Maxima terhadap motivasi dan prestasi belajar pada pokok bahasan matriks pada siswa Madrasah Aliyah Negeri 1 Yogyakarta. Proses pengumpulan data dilaksanakan melalui dua siklus. Hasil penelitian menunjukkan website eLearning Moodle berbantuan CAS Maxima mampu meningkatkan motivasi dan prestasi belajar siswa ditunjukkan dengan sebelum menggunakan media website eLearning Moodle berbantuan CAS Maxima menunjukkan hasil yang kurang memuaskan hanya sebesar 39\% yang memenuhi KKM, siklus I ketuntasan mencapai 84,375\%, siklus II ketuntasan mencapai 100\%. Motivasi belajar pada tindakan pra siklus memperoleh persentase $18 \%$ atau sangat rendah pada indikator rasa ingin tahu, tekun dan ulet dalam menghadapi kesulitan memperoleh persentase $26 \%$ atau kategori rendah, tidak memerlukan dorongan dari luar untuk berprestasi memperoleh persentase $20 \%$ atau kategori sangat rendah dan senang dan rajin belajar $30 \%$ berada pada kategori rendah. Pada siklus 1 terjadi peningkatan motivasi belajar yaitu semua indikator berada pada kategori sedang. Sedangkan pada siklus 2 terjadi peningkatan motivasi belajar semua indikator berada pada kategori tinggi.
\end{abstract}

Kata kunci: Computer algebra system; moodle; motivasi; prestasi.

\begin{abstract}
The purpose of this study was to determine whether the influence of Maxima's Computer Algebra System (CAS) eLearning Moodle website on motivation and learning achievement on the subject matter of the matrix on students of Madrasah Aliyah Negeri 1 Yogyakarta. The data collection process is carried out through two cycles. The results showed the Moodle eLearning website assisted by CAS Maxima able to improve students' motivation and learning achievement indicated by using the CAS Maxima-assisted eLearning website media showed unsatisfactory results of only 39\% that met the KKM, the first cycle of completeness reached $84.375 \%$, the second cycle of completeness reached $100 \%$ Motivation to learn in pre-cycle actions get a percentage of $18 \%$ or very low on indicators of curiosity, perseverance and resilience in the face of difficulty obtaining a percentage of $26 \%$ or low category, does not require outside encouragement to achieve achievement percentage of $20 \%$ or very low and happy categories and 30\% study diligently in the low category. In cycle 1 an increase in motivation to learn that all indicators are in the medium category. Whereas in cycle 2 an increase in motivation to learn all the indicators are in the high category.
\end{abstract}

Keywords: Achievement; computer algebra system; moodle; motivation.

\section{PENDAHULUAN}

Matematika memiliki hubungan yang erat dengan teknologi. Dalam dua dekade terakhir telah muncul bermacam-macam variasi teknologi yang dapat digunakan oleh guru dan siswa dalam melaksanakan pembelajaran matematika.

Association

Mathematics Teacher Educators (AMTE) merekomendasikan guru matematika haruslah diberikan kesempatan memperoleh pengetahuan dan pengalaman untuk menggabungkan teknologi dalam pengajaran dan 
pembelajaran matematika (McCulloch et al., 2018). Tuntutan abad 21 mengharuskan guru harus menguasai pemanfaatan informasi, media, dan teknologi (IMT) untuk diajarkan ke siswa, karena penguasaan teknologi dapat membantu siswa meraih kesuksesan hidup dan karir dimasa depan (Emily, Tee, \& Jr, 2018). Di era digital saat ini seharusnya guru sudah memahami teknologi untuk meningkatkan kualitas belajar matematika, karena teknologi memfasilitasi suatu pendekatan baru untuk menyelesaikan masalah melalui aspek dinamis dengan menggunakan software (Bray \& Tangney, 2017).

Salah satu cara mengintegrasikan teknologi dalam proses pembelajaran matematika adalah dengan memanfaatkan laboratorium komputer sebagai sarana pembelajaran matematika, memanfaatkan internet untuk pembelajaran Online, dan mengajarkan siswa cara menggunakan software matematika. Salah satu bentuk dari pemanfaatan teknologi dalam pembelajaran matematika adalah dengan menggunakan Learning Management System Moodle sebagai sarana media Online yang dapat digunakan dalam kegiatan aktivitas pembelajaran (Handayanto, Supandi, \& Ariyanto, 2018). Moodle adalah open source Learning Management System (LMS) yang menawarkan berbagai macam variasi teknologi dalam pembelajaran matematika (Blanco \& Ginovart, 2012).

Moodle merupakan platform yang menyediakan konten matematika yang interaktif yang membuat guru dan siswa dapat dengan mudah saling berinteraksi. Moodle memiliki potensi yang dapat diperluas dengan berbagai teknologi yang inovatif (Brijlall \& Maharaj,
2017). Moodle dapat membuat siswa saling berkomunikasi dengan guru untuk membahas materi pelajaran tanpa harus menunggu waktu jam pelajaran sekolah untuk dapat bertemu langsung sehingga membuat pembelajaran lebih fleksibel. Dengan menggunakan Moodle guru dapat mengunggah materi agar menjadi sumber bacaan bagi siswa dan dapat diakses secara online (Takaendengan \& Santosa, 2018), tulisan yang ada di papan tulis dapat diganti dengan materi yang diunggah di Moodle agar dapat diakses secara online (Farjon, Smits, \& Voogt, 2018).

Dengan menggunakan Computer Algebra System (CAS) seperti Maxima dapat meningkatkan motivasi belajar siswa sesuai dengan pendapat (Ye. Velychko, V. Stopkin, \& H. Fedorenko, 2019) "The using of Computer Algebra System Maxima can positively affects the motivation of students to study the material and gives impetus to the search for new algorithms for solving various mathematical problems" artinya adalah dengan menggunakan CAS Maxima maka siswa akan termotivasi untuk menerapkan algoritma untuk menyelesaikan soal matematika dengan berbagai macam cara yang beraneka ragam. Disisi lain (Waheed, 2013) berpendapat bahwa Moodle dapat meningkatkan motivasi belajar siswa melalui kegiatan atau aktivitas yang melibatkan fasilitasfasilitas yang ada di Moodle. Sejalan dengan pendapat ini (Lin, Tseng, \& Chiang, 2016) juga berpendapat bahwa media komputer dapat meningkatkan motivasi belajar siswa karena dapat membuat masalah yang abstrak menjadi mudah dipahami.

Motivasi belajar sangat berpengaruh pada prestasi belajar siswa. Hal ini sesuai dengan pendapat Özen 
(2017) para peneliti pendidikan percaya bahwa motivasi adalah faktor yang sangat penting guna meningkatkan prestasi belajar siswa. Sebaliknya prestasi belajar memiliki pengaruh terhadap motivasi belajar seperti yang dikatakan oleh (Nihan, 2017) "the learning achievement has an important effect on student's motivation learning. The factors affecting academic achievement can increase are attitude and motivation" yang artinya faktor yang dapat mempengaruhi prestasi siswa dapat meningkat adalah tingkah laku dan motivasi. Berdasarkan pendapat tersebut dapat disimpulkan secara teoritis bahwa semakin tinggi motivasi belajar siswa maka semakin tinggi prestasi yang dimiliki oleh siswa.

Dari beberapa penelitian tersebut, belum ada penelitian yang menggabung-kan Moodle dan CAS Maxima sekaligus untuk mengamati motivasi dan hasil belajar. Melihat potensi yang ada pada Moodle dan CAS Maxima maka dibuat platform Moodle berbantuan CAS Maxima untuk meningkatkan motivasi dan prestasi belajar untuk siswa Madrasah Aliyah Negeri 1 Yogyakarta.

Hasil tindakan pra siklus menunjukkan adanya $39 \%$ atau 12 siswa sudah mencapai Kriteria Ketuntasan Minimal (KKM), sebanyak $61 \%$ atau 20 siswa masih di bawah KKM. Nilai rata-rata pada tes prestasi di pra-siklus sebesar 52,31. Hasil tindakan pra siklus menunjukkan bahwa ada faktor-faktor yang menyebabkan sebagian tidak termotivasi memanfaatkan teknologi dan prestasi belajar siswa rendah yaitu : (1) siswa kurang memiliki rasa ingin tahu pada materi pembelajaran yang disampaikan oleh guru karena metode yang digunakan guru kurang menarik dan terkesan monoton dalam hal ini proses pembelajaran masih menggunakan metode konvensional belum memafaatkan teknologi seperti website eLearning berbantuan CAS Maxima, (2) siswa cenderung merasa jenuh dan bosan dikarenakan kurangnya variasi dalam penyampaian materi dalam proses pembelajaran matematika sehingga siswa cenderung kurang memperhatikan guru, (3) masih banyak ditemukan siswa yang merasa kesulitan pada saat mengerjakan soal matriks dan (4) siswa masih membutuhkan apresiasi dan motivasi dari guru untuk belajar.

Adapun tujuan dari penelitan ini adalah untuk meningkatkan motivasi dan prestasi belajar matematika siswa kelas XI MAN 1 Yogyakarta melalui pemanfaatan Learning Management System Moodle berbantuan CAS Maxima.

\section{METODE PENELITIAN}

Jenis penelitian ini adalah Penelitian Tindakan Kelas (PTK) yang berlangsung selama 15 Oktober sampai 17 Desember 2019 di MAN 1 Yogyakarta. Subjek dalam penelitian ini adalah seluru siswa kelas XI-IPA 2 yang terdiri dari 32 siswa. Materi matriks diajarkan untuk siswa SMA/MA kelas XI semester 1 dengan sub pokok bahasan (1) penjumlahan dan pengurangan matriks, (2) perkalian matriks dengan skalar dan perkalian antar matriks, (3) determinan matriks persegi dan (4) invers matriks persegi.

Dalam penelitian ini mengikuti langkah-langkah dari penelitian tindakan kelas (Marom \& Sugiman, 2017) sebagai berikut.

1. Pelaksanaan

Merencanakan pelaksanaan pembelajaran dengan setting blended learning bersama guru. Dalam 
pelaksanaan pembelajaran dengan memanfaatkan LMS berbantuan Maxima dilaksanakan di laboratorium komputer. Adapun kegiatan pembelajaran yang akan dilaksanakan sebagai berikut:

a. Menyusun Rencana Pelaksanaan Pembelajaran (RPP)

b. Membuat pedoman observasi pelaksanaan pembelajaran di laboratorium komputer

c. Membuat soal matriks kemudian di distribusikan di website eLearning Moodle

d. Membuat video pembelajaran kemudian di unggah di Moodle.

\section{Pengamatan}

Siswa mengerjakan soal-soal matriks yang di LMS. Soal-soal matriks dikerjakan menggunakan CAS Maxima. Setelah soal-soal matriks dikerjakan siswa mengirim jawabannya berupa komputasi simbolik yang digunakan pada perhitungan matriks. Jawaban siswa berupa komputasi simbolik inilah yang kemudian diobservasi dan dianalisis.

\section{Refleksi}

Data yang diperoleh saat observasi dianalisis, kemudian dilakukan refleksi untuk mengevaluasi penelitian yang telah berjalan pada siklus pertama serta untuk memperoleh perbaikan-perbaikan dalam pelaksanaan siklus selanjutnya agar berjalan sesuai dengan tujuan penelitian.

\section{Mengulangi proses perencanaan}

Mengikuti langkah-langkah pada siklus sebelumnya untuk memperbaiki tahapan pelaksanaan pembelajaran pada siklus sebelumnya.
5. Melaksanakan observasi kembali

Siswa mengerjakan soal-soal matriks yang di LMS. Soal-soal matriks dikerjakan menggunakan Maxima. Setelah soal-soal matriks dikerjakan siswa mengirim jawabannya berupa komputasi simbolik yang digunakan pada perhitungan matriks. Jawaban siswa berupa komputasi simbolik inilah yang kemudian diobservasi dan dianalisis.

6. Merefleksi Kembali dan seterusnya Pada tahap ini peneliti menganalisis dan mengevaluasi rangkaian kegiatan pembelajaran yang sudah dilakukan pada siklus pertama. Apabila masih belum menemukan kriteria yang diinginkan maka proses dilanjutkan lagi pada siklus berikutnya sampai memenuhi kriteria yang diinginkan yaitu telah tercapai motivasi belajar siswa $>60$ dan nilai siswa telah memenuhi KKM > 75 maka proses siklus pembelajaran dianggap berhasil. Adapun cara menentukan motivasi belajar siswa adalah menentukan terlebih dahulu kategori-kategori penilaian yang akan diberikan kepada siswa adalah sangat tinggi, tinggi, sedang, rendah dan sangat rendah. Jadi terdapat lima kategori kemudian dipilih persentase maksimum yang akan diberikan kepada siswa yaitu sebesar $100 \%$. Rumus untuk menentukan persentase motivasi belajar

$\mathrm{P}=\frac{\text { skor total presentase }}{\text { total kriteria penilaian }}=\frac{100}{5}=20$,

sehingga diperoleh tiap-tiap interval untuk masing-masing kategori adalah 20 (Nugroho, 2016) seperti yang ditunjukkan pada Tabel 1. 
DOI: https://doi.org/10.24127/ajpm.v9i1.2657

Tabel 1. Interval kriteria penilaian.

\begin{tabular}{cll}
\hline No & $\begin{array}{l}\text { Interval } \\
\text { penilaian }\end{array}$ & $\begin{array}{l}\text { Kriteria } \\
\text { penilaian }\end{array}$ \\
\hline 1. & $80<\mathrm{P} \leq 100$ & Sangat tinggi \\
2. & $60<\mathrm{P} \leq 80$ & Tinggi \\
3. & $40<\mathrm{P} \leq 60$ & Sedang \\
4. & $20<\mathrm{P} \leq 40$ & Rendah \\
5. & $0<\mathrm{P} \leq 20$ & Sangat rendah \\
\hline
\end{tabular}

Indikator dinilai pada motivasi belajar siswa adalah rasa ingin tahu, tekun dan ulet dalam menghadapi kesulitan, tidak memerlukan dorongan dari luar untuk berprestasi, senang dan rajin belajar (Murayama, FitzGibbon, and Sakaki 2019; Star et al. 2014) ditunjukkan pada Tabel 2.
Teknik penilaian yang digunakan adalah skala likert terdiri dari lima skala yaitu sangat setuju, setuju, netral, tidak setuju dan tidak sangat setuju. Cara pemberian nilai untuk skala likert yaitu pertanyaan negatif bernilai 1 jika siswa menjawab 5, bernilai 2 jika siswa menjawab 4 dan seterusnya sedangkan pertanyaan positif penilaiannya kebalikan dari penilaian negatif. Cara menentukan besarnya persentase untuk setiap indikator motivasi belajar adalah $\frac{\text { jumlah skor angket siswa }}{\text { jumlah skor angket maksimum }} \times 100 \%$,

dimana jumlah skor angket maksimum diperoleh dari jumlah siswa $\times$ skor maksimum angket $\times$ jumlah item.

Tabel 2. Aspek-aspek dan indikator motivasi belajar.

\begin{tabular}{|c|c|c|}
\hline No & Aspek atau indikator & Deskripsi \\
\hline 1. & Rasa ingin tahu & $\begin{array}{l}\text { Siswa memiliki rasa ingin tahu terhadap } \\
\text { penggunaan teknologi }\end{array}$ \\
\hline 2. & $\begin{array}{l}\text { Tekun dan ulet dalam } \\
\text { menghadapi kesulitan }\end{array}$ & $\begin{array}{l}\text { Siswa tidak mudah menyerah meskipun } \\
\text { hasil komputasi menggunakan program } \\
\text { komputer selalu gagal }\end{array}$ \\
\hline 3. & $\begin{array}{l}\text { Tidak memerlukan dorongan } \\
\text { dari luar untuk berprestasi }\end{array}$ & $\begin{array}{l}\text { Siswa dapat belajar secara mandiri tanpa } \\
\text { perlu diingatkan oleh guru menggunakan } \\
\text { web eLearning Moodle }\end{array}$ \\
\hline 4. & Senang dan rajin belajar & $\begin{array}{l}\text { Siswa senang belajar menggunakan Moodle } \\
\text { dan Maxima }\end{array}$ \\
\hline
\end{tabular}

HASIL DAN PEMBAHASAN

Dengan menggunakan Website elerning Moodle berbantuan Maxima (Gambar 1), siswa dapat termotivasi untuk belajar Matriks karena tersedia banyak tutorial pembelajaran matriks yang menarik. Tersedia juga soal-soal yang dapat dikerjakan dengan menggunakan Maxima. Salah satu kelebihan dari aplikasi website eLearning berbantuan Maxima adalah menghilangkan batasan-batasan belajar, siswa dapat mengatur sendiri jadwal belajar mereka karena pelajaran dapat diakses secara online. Apabila siswa belum memahami pelajaran siswa dapat langsung berdiskusi dengan guru di forum diskusi Moodle.

\section{Hasil tindakan siklus 1.}

Pada siklus I terjadi peningkatan banyaknya siswa yang telah mencapai KKM sebesar $73 \%$ atau 23 siswa dan 
sebanyak $27 \%$ atau 9 siswa yang belum mencapai KKM. Nilai rata-rata siswa meningkat menjadi 78,90. Sedangkan pada motivasi belajar menunjukkan bahwa sebanyak $18 \%$ atau 7 siswa yang memiliki rasa ingin tahu sangat rendah terhadap pemanfaatan teknologi seperti website eLearning dan program komputer untuk menyelesaikan masalah matematika. Hal ini dapat terjadi karena siswa belum terbiasa menggunakan program komputer. Pada indikator kedua hanya ada $26 \%$ atau 8 siswa yang tekun dan ulet dalam mengerjakan soal matematika menggunakan program komputer. Hal ini dikarenakan siswa belum memahami cara kerja perintahperintah pada program Maxima sehingga terdapat error siswa mudah menyerah dan malu bertanya pada guru. Pada indikator ketiga hanya ada $20 \%$ atau 6 siswa yang tidak membutuhkan apresiasi dan motivasi oleh guru untuk belajar. Hasil motivasi belajar matematika menggunakan teknologi seperti internet, website dan software matematika ditunjukkan pada Tabel 3

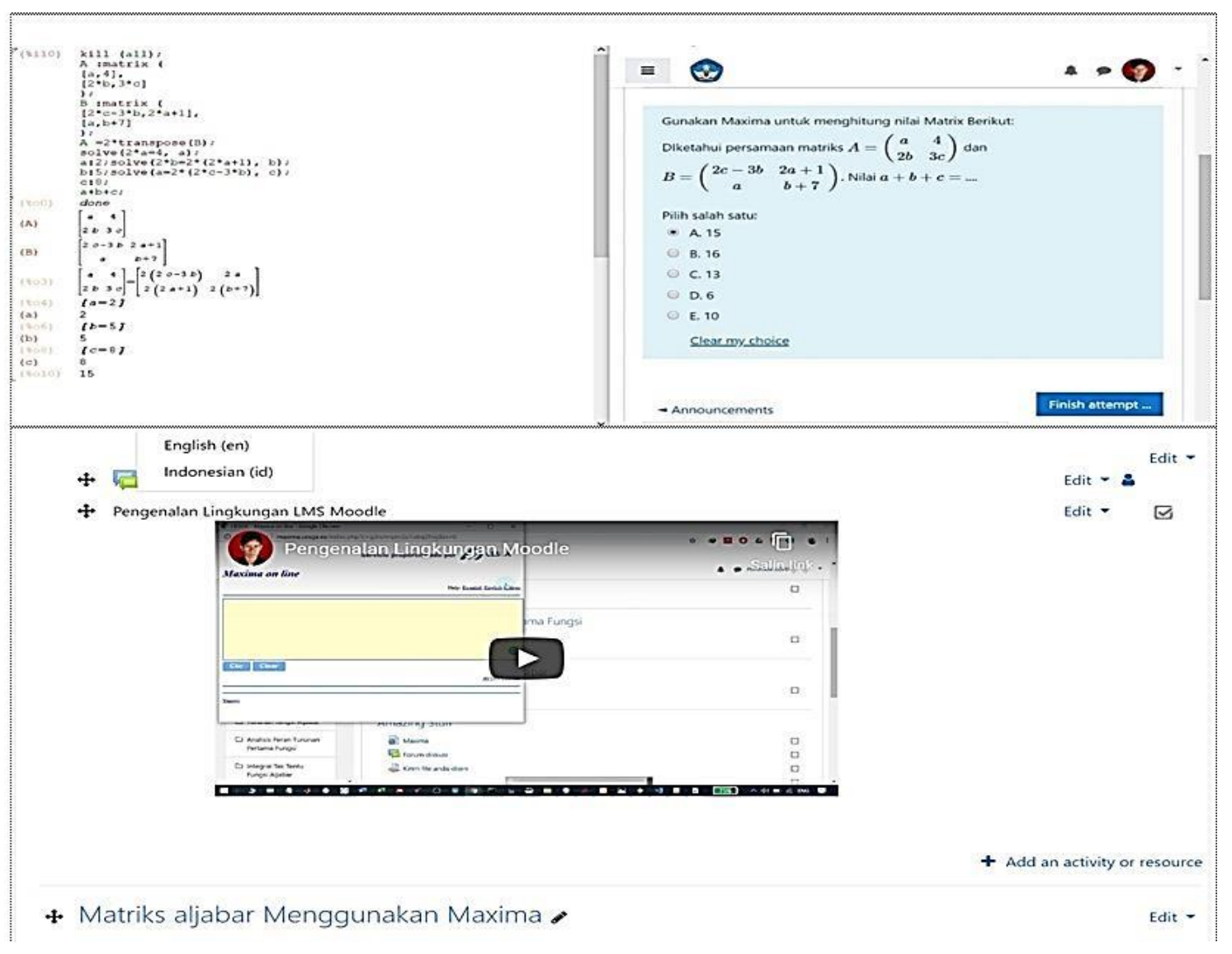

\section{Gambar 1. Tampilan Website Moodle Berbantuan CAS Maxima}

Hasil angket motivasi belajar siswa pada Tabel 3 masih banyak siswa kurang memiliki motivasi belajar matematika menggunakan teknologi namun meskipun motivasi belajar siswa di siklus 1 rendah, tapi motivasi belajar siswa pada siklus 1 masih lebih baik daripada motivasi belajar pada tindakan pra siklus. 
DOI: https://doi.org/10.24127/ajpm.v9i1.2657

Tabel 3. Motivasi belajar pada siklus 1 .

\begin{tabular}{clcc}
\hline No & \multicolumn{1}{c}{ Aspek atau indikator } & Persentase & Kategori \\
\hline 1. & Rasa ingin tahu & $55 \%$ & Sedang \\
2. & Tekun dan ulet dalam menghadapi kesulitan & $47 \%$ & Sedang \\
3. & Tidak memerlukan dorongan dari luar untuk berprestasi & $45 \%$ & Sedang \\
4. & Senang dan rajin belajar & $38 \%$ & Sedang \\
\hline
\end{tabular}

\section{Hasil tindakan siklus 2}

Dari hasil pengamatan motivasi belajar pada siklus 1 masih ada siswa yang memiliki motivasi rendah dan ada 5 siswa yang masih mendapatkan nilai di bawah KKM oleh karena itu perlu dilakukan tindakan pada siklus 2. Pada tahapan siklus 1, dilakukan tiga kali tindakan yang mana terdiri dari dua pertemuan pembelajaran matriks menggunakan website eLearning Moodle berbantuan CAS Maxima.

1. Pada tindakan di siklus 1, siswa masih merasa kesulitan menggunakan program Maxima, kesulitan yang dialami adalah kesalahan membuat variabel, salah memasukkan kurang, lupa titik koma dan lain-lain sehingga program yang dibuat oleh siswa menjadi error sehingga siswa kurang termotivasi menggunakan program Maxima. Upaya yang dilakukan oleh peneliti dan dibantu oleh guru untuk mengurangi kesalahan penginputan pada program Maxima adalah dengan menambah video tutorial Matriks menggunakan program Maxima, Memperlengkap Modul Matriks menggunakan Maxima dan membuat sesi Q \& A (tanya jawab seputar matriks menggunakan Maxima sehingga error dapat berkurang dan siswa termotivasi belajar matriks menggunakan Maxima.

2. Pada siklus 1 siswa kurang termotivasi untuk belajar matriks menggunakan Website eLearning berbantuan Maxima hanya sekitar 14 orang dari 32 siswa yang membuka website eLearning yang dibuat oleh peneliti. Cara mengatasinya adalah dengan membuat kuis tantangan yang intuitif yaitu dengan cara mengadakan lomba kecil-kecilan untuk menjawab soal Matriks yang diberikan oleh peneliti. Adapun siswa yang mendapatkan high score (skor) tertinggi untuk kategori juara satu, dua, dan seterusnya Namanya akan ditampilkan di halaman depan website sehingga siswa berlomba-lomba mengerjakan soal matriks menggunakan Maxima. Adapun untuk juara satu, dua dan tiga yang menang akan diberikan apresiasi berupa pemberian sertifikat yang diberikan oleh peneliti kepada siswa pemenang dan siswa pun sangat senang dan siswa pun termotivasi.

3. Pada siklus 1 siswa belum bisa belajar mandiri tanpa bantuan dari guru, sedangkan pada siklus 2, siswa sudah terbiasa menggunakan program Maxima, dan siswa pun sangat aktif di forum diskusi yang dibuat oleh peneliti untuk membahas soal kerja kelompok yang diberikan oleh peneliti dan siswa merasa termotivasi dalam mengerjakan soal matriks menggunakan Maxima karena siswa percaya kalau bisa mengerjakan seluruh soal maka mereka bisa menjadi programmer yang handal kelak dikemudian hari.

Karena beberapa alasan inilah motivasi belajar siswa dapat meningkat yang ditunjukkan pada Tabel 4 . 
DOI: https://doi.org/10.24127/ajpm.v9i1.2657

Tabel 4. Motivasi belajar siklus 2.

\begin{tabular}{clcc}
\hline No & \multicolumn{1}{c}{ Aspek atau indikator } & Persentase & Kategori \\
\hline 1 & Rasa ingin tahu & $76 \%$ & Tinggi \\
2 & Tekun dan ulet dalam menghadapi kesulitan & $69 \%$ & Tinggi \\
3 & Tidak memerlukan dorongan dari luar untuk berprestasi & $64 \%$ & Tinggi \\
4 & Senang dan rajin belajar & $66 \%$ & Tinggi \\
\hline
\end{tabular}

Pada Tabel 4 seluruh siswa memiliki motivasi yang tinggi dalam menggunakan teknologi seperti web eLearning Moodle dan program Maxima. Hal ini menunjukkan bahwa teknologi dapat membuat siswa termotivasi belajar matematika seperti rajin menggunakan program Maxima, sering mengerjakan soal matriks, siswa dapat belajar secara mandiri tanpa perlu diingatkan oleh guru menggunakan web eLearning Moodle dan menggunakan program Maxima untuk menyelesaikan masalah matriks dan pembuktian jawaban. Untuk lebih jelas melihat selisih antara motivasi siswa pada pra siklus, siklus 1 dan siklus 2 pada hasil tindakan dapat dilihat pada Gambar 2.
Dari Gambar 2 dapat dilihat cukup jelas bahwa motivasi belajar matematika pada siklus 2 jauh lebih tinggi dibandingkan dengan motivasi belajar pada siklus 1 dan pra siklus. Hasil angket akhir motivasi belajar siswa telah mengalami peningkatan jauh dibandingkan dengan motivasi pada pra siklus, siklus 1. Dari hasil penelitian yang diperoleh bedasarkan data-data yang sudah terkumpul, maka diketahui bahwa penggunaan Moodle berbantuan CAS pada pembelajaran matriks dapat meningkatkan motivasi belajar. Hal ini dibuktikan dengan peningkatan motivasi belajar siswa selama pembelajaran berlangsung. Hasil pengamatan pada setiap siklus diperoleh data motivasi belajar seperti pada Tabel 6.

\section{Selisih Motivasi Awal dan Akhir}

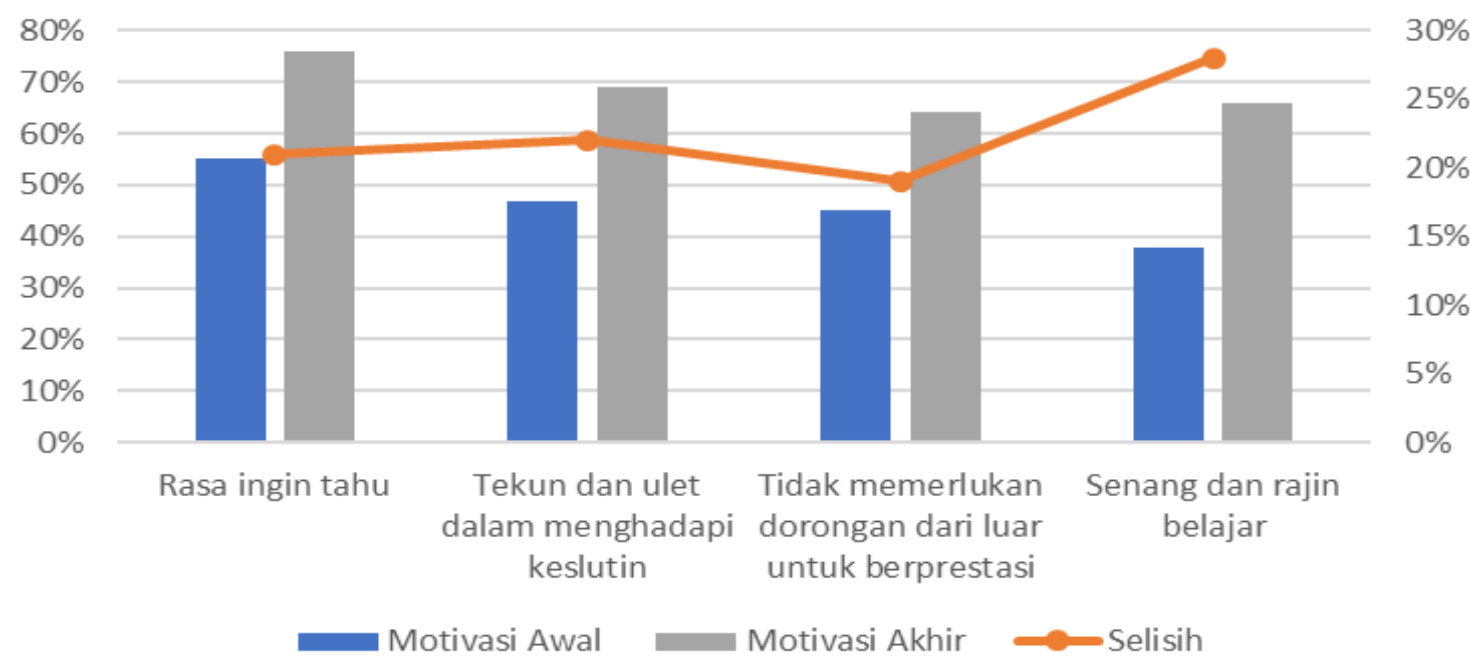

Gambar 2. Diagram batang selisih motivasi belajar siklus 1 dan siklus 2 . 
DOI: https://doi.org/10.24127/ajpm.v9i1.2657

Tabel 6. Kategori ketuntasan pada pra siklus, siklus 1 dan siklus 2.

\begin{tabular}{cccc}
\hline Kategori Ketuntasan & Pra siklus & Siklus 1 & Siklus 2 \\
\hline Tuntas & $39 \%$ & $84,375 \%$ & $100 \%$ \\
& $(12$ siswa) & $(27$ siswa) & $(32$ siswa) \\
Tidak Tuntas & $61 \%$ & $15,625 \%$ & $0 \%$ \\
& $(20$ siswa) & $(5$ siswa). & (tidak ada) \\
Nilai Rata-Rata & 52,31 & $78,90$. & 88,63 \\
\hline
\end{tabular}

Hasil dari Penelitian Tindakan Kelas (PTK) yang telah dilaksanakan menunjukkan prestasi siswa MAN 1 Yogyakarta mengalami peningkatan signifikan dari sebelum dilaksanakan tindakan sampai sesudah selesai tindakan. Prestasi siswa tersebut meliputi hasil perolehan dalam mengerjakan soal tes dari tindakan pra siklus sampai pada siklus II. Dari hasil siklus II semua siswa telah mencapai KKM, karena tidak ada siswa yang nilainya di bawah KKM dan siswa sudah memiliki motivasi yang tinggi untuk belajar matematika maka pembelajaran dianggap tuntas.

Moodle adalah LMS berbasis server online sedangkan CAS Maxima adalah software Matematika untuk memanipulasi bentuk fungsi aljabar. CAS Maxima adalah software berbasis offline, dengan menempatkan CAS Maxima di server online membuat CAS Maxima lebih mudah di akses tanpa memerlukan spesifikasi laptop atau komputer yang tinggi dan fleksibel (dapat diakses dimana saja selama tersedia jaringan internet) sehingga siswa lebih termotivasi untuk belajar menggunakan CAS Maxima untuk menyelesaikan masalah aljabar matriks.

$$
\text { Dengan menggunakan CAS }
$$

Maxima dapat membuat siswa lebih memahami konsep matriks khususnya pada operasi perkalian antar matriks dan invers matriks yang masih dianggap sulit oleh sebagian siswa, dengan menggunakan CAS Maxima siswa dengan mudah menentukan hasil perhitungan matriks aljabar dan pembuktian jawaban matriks dengan sangat akurat. Kekurangan dari LMS Moodle berbantuan CAS Maxima adalah hanya dapat diakses menggunakan internet (online), sedangkan kelebihannya adalah (1) tidak memerlukan laptop atau komputer dengan spesifikasi tinggi (2) dapat di jalankan menggunakan smartphone (3) dapat dijalankan menggunakan semua Operating System seperti windows, Linux dan Macintosh (MacBook).

Hasil penelitian ini sejalan dengan penelitian yang sudah dilakukan oleh banyak peneliti seperti (Handayanto, Supandi, \& Ariyanto, 2018); (Blanco \& Ginovart, 2012); (Brijlall \& Maharaj, 2017); (Takaendengan \& Santosa, 2018) yang menyatakan bahwa penggunaan LMS seperti Moodle sangat baik dan memiliki dampak yang positif dalam proses pembelajaran. Selain itu, penelitian ini juga sejalan dengan (Ye. Velychko, V. Stopkin, \& H. Fedorenko, 2019) yang menyatakan bahwa CAS Maxima sangat membantu dalam proses pembelajaran.

\section{KESIMPULAN DAN SARAN}

Berdasarkan dari hasil penelitian yang sudah dilakukan mengenai optimalisasi motivasi dan prestasi belajar siswa menggunakan Moodle berbantuan Computer Algebra System 
(CAS) maka dapat disimpulkan bahwa penggunaan media pembelajaran seperti website eLearning Moodle berbantuan CAS Maxima dalam pembelajaran matematika pada pokok bahasan matriks mampu meningkatkan prestasi dan motivasi belajar matematika.

Untuk penelitian selanjutnya disarankan agar selalu melakukan inovasi dalam pembelajaran matematika yang sesuai dengan karakter siswa supaya kebutuhan pembelajaran dapat terpenuhi. Kemudian sebagai seorang guru hendaknya selalu melibatkan secara aktif para siswa dalam mengikuti proses pembelajaran matematika di dalam kelas. Disarankan juga kepada para pendidik hendaknya menyiapkan segala sesuatu yang diperlukan baik itu metode maupun media pembelajaran dengan baik khususnya yang berbasis bahasa pemrograman yang dinamis sehingga dapat membuat sebuah simulasi dari konsep matematika sehingga dapat mengurangi tingkat abstraksi siswa dalam proses pembelajaran matematika.

\section{DAFTAR PUSTAKA}

Blanco, M., \& Ginovart, M. (2012). On How Moodle Quizzes Can Contribute to the Formative EAssessment of First-Year Engineering Students in Mathematics Courses. RUSC, Universities and Knowledge Society Journal, 9(1), 354-70. https://doi.org/10.7238/rusc.v9i1.1 277.

Bray, A., \& Tangney, B. (2017). Technology Usage in Mathematics Education Research - A Systematic Review of Recent Trends. Computers \& Education, 114, 255-273.

Brijlall, D., \& Maharaj, A. (2017). Exploring MOODLE as a Platform in Promoting Effective Mathematics Teaching and Learning. PONTE International Scientific Researchs Journal, 73(6).

Emily, O., Tee, P., \& Jr, F. M. (2018). Coherently Connecting Computer and Information Literacy Classroom and Accountability Assessments. Journal of Physics: Conference Series, 1065: 22010.

Farjon, D., Smits, A., \& Voogt, J. (2018). Technology Integration of Pre-Service Teachers Explained by Attitudes and Beliefs, Competency, Access, and Experience. Computers \& Education.

https://doi.org/10.1016/j.compedu. 2018.11.010

Handayanto, A., Supandi, S., \& Ariyanto, L. (2018). Teaching Using Moodle in Mathematics Education. Journal of Physics: Conference Series, 1013: 12128.

Lin, Y. W., Tseng, C. L., \& Chiang, P. J. (2016). The Effect of Blended Learning in Mathematics Course. EURASIA Journal of Mathematics Science and Technology Education, 13(3), 741-770.

Marom, S., \& Sugiman. (2017). Upaya Meningkatkan Prestasi Belajar Matematika Berbasis Wolframs Mathematica Pada Siswa Kelas IV SDN 4 Muryolobo Tahun Pelajaran 2016/2017. Jurnal Ilmiah Pendidikan Matematika, 2(1), 8596.

McCulloch, A. W., et al. (2018). Factors That Influence Secondary Mathematics Teachers' Integration of Technology in Mathematics Lessons. Computers \& Education, 123, 1-50. https://doi.org/10.1016/j.compedu. 2018.04.008. 
Murayama, K., FitzGibbon, L., \& Sakaki, M. (2019). Process Account of Curiosity and Interest: A Reward-Learning Perspective. Educational Psychology Review, 31(4), 875-95. https://doi.org/10.1007/s10648019-09499-9.

Nihan, S. (2017). The Effect of Attitude on Student Achievement. In The Factors Effecting Student Achievement: Meta-Analysis of Empirical Studies, Springer International Publishing, 57.

Nugroho, M. H. (2016). Penerapan Model Pembelajaran Realistic Mathematics Education (RME) Untuk Meningkatkan Motivasi Dan Prestasi Belajar Matematika Materi Statistika Pada Peserta Didik Kelas XI TP3RP SMK Negeri 1 Kendal Tahun Pelajaran 2015/2016. Journal of Medives: Journal of Mathematics Education IKIP Veteran Semarang.

Özen, S. O. (2017). The Effect of Motivation on Student Achievement." In The Factors Effecting Student Achievement: Meta-Analysis of Empirical Studies, 35-56.

Takaendengan, B. R., \& Santosa, R. H. (2018). Using Moodle to Improve Self-Directed Learning of Mathematics in Vocational School. Journal of Physics: Conference Series, 1097: 12121.

Star, J. R., et al. (2014). Studying Technology-Based Strategies for Enhancing Motivation in Mathematics. International Journal of STEM Education, 1(1), 1-19.

Waheed, M. (2013). Influence of Moodle Module Features on Student Motivation to Use ELearning System.
Velychko, V. Y., Stopkin, A. V., \& Fedorenko, O. H. (2019). Use Of Computer Algebra System Maxima In The Process of Teaching Future Mathematics Teachers. Information Technologies and Learning Tools, 69: 112. 